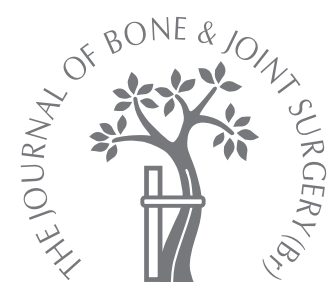

C. J. Moran,

F. J. Shannon,

F. P. Barry,

J. M. O’Byrne,

T. O'Brien,

W. Curtin,

From the

Regenerative

Medicine Institute,

National University

of Ireland, Galway,

Ireland and Royal

College of Surgeons

in Ireland

ANNOTATION

\title{
Translation of science to surgery
}

\author{
LINKING EMERGING CONCEPTS IN BIOLOGICAL CARTILAGE \\ REPAIR TO SURGICAL INTERVENTION
}

Orthopaedic surgery is in an exciting transitional period as modern surgical interventions, implants and scientific developments are providing new therapeutic options. As advances in basic science and technology improve our understanding of the pathology and repair of musculoskeletal tissue, traditional operations may be replaced by newer, less invasive procedures which are more appropriately targeted at the underlying pathophysiology. However, evidence-based practice will remain a basic requirement of care. Orthopaedic surgeons can and should remain at the forefront of the development of novel therapeutic interventions and their application. Progression of the potential of bench research into an improved array of orthopaedic treatments in an effective yet safe manner will require the development of a subgroup of specialists with extended training in research to play an important role in bridging the gap between laboratory science and clinical practice. International regulations regarding the introduction of new biological treatments will place an additional burden on the mechanisms of this translational process, and orthopaedic surgeons who are trained in science, surgery and the regulatory environment will be essential. Training and supporting individuals with these skills requires special consideration and discussion by the orthopaedic community.

In this paper we review some traditional approaches to the integration of orthopaedic science and surgery, the therapeutic potential of current regenerative biomedical science for cartilage repair and ways in which we may develop surgeons with the skills required to translate scientific discovery into effective and properly assessed orthopaedic treatments.

It has been observed that it took more than 2000 years for practitioners of orthopaedic surgery to value and apply principles and observations derived from basic research. ${ }^{1}$ Yet, in the short time since this occurred, the understanding that optimal patient care depends on the science, as well as surgery, has transformed orthopaedic practice from a disparate array of manipulations and operations to a range of treatments that, in many instances, result in life-changing improvements for patients. ${ }^{2-10}$

We now live in a time when the integration of knowledge from new basic research into orthopaedic practice offers the potential to solve major clinical problems, including the pain and loss of mobility caused by the limited capacity of human joints for repair. As advances in technology further improve techniques of tissue repair, the orthopaedic operations of yesterday may be replaced with newer, less invasive and more relevant procedures. Advances in tissue engineering, molecular biology, stem cell therapy and gene therapy may prevent certain musculoskeletal conditions from ever reaching the point of requiring surgical intervention. ${ }^{11,12}$ This evolution, driven by patient need and advances in science and technology, will present fundamental challenges to orthopaedic surgeons. ${ }^{13-15}$ In order to take full advantage of the available and emerging technologies, we will need a body of surgeons who understand the capabilities and limitations of these procedures as well as their clinical and biological reality, so that the new science can be translated into real yet safe benefits for our patients (Table I). These clinicianscientists will work closely with clinical colleagues and basic scientists to ensure that fundamental discoveries in the laboratory are translated into effective treatments (Fig. 1).

In this paper we briefly review some traditional approaches to the integration of orthopaedic science and surgery, the therapeutic potential of current regenerative biomedical science, and ways in which we may develop a new cadre of surgeons with the required skill set to translate cutting-edge scientific discovery in regenerative medicine into evidence-based surgical intervention for cartilage injury and related conditions. 
Table I. Fields in which the orthopaedic clinician-scientist should have formal training in addition to standard higher surgical training. Included are the tools and skills needed in each of these fields

\begin{tabular}{|c|c|}
\hline Field & Tools and skills needed \\
\hline Biomedical research & $\begin{array}{l}\text { Comprehensive knowledge of the field, ability to perform solid bench work and knowledge of appropriate } \\
\text { study design }\end{array}$ \\
\hline Intellectual property & $\begin{array}{l}\text { Access to experts for development and protection, basic understanding of the process, strategies and } \\
\text { importance of intellectual property, and knowledge of patents }\end{array}$ \\
\hline Funding & $\begin{array}{l}\text { Knowledge of funding sources, ability to negotiate and ability to develop contacts in government and indus- } \\
\text { try }\end{array}$ \\
\hline Regulatory agencies & $\begin{array}{l}\text { Knowledge of various regulatory bodies (national, international and supranational), ability to navigate } \\
\text { through the system and awareness of forms, processes }\end{array}$ \\
\hline Legal issues & $\begin{array}{l}\text { Awareness of intellectual property laws, patients' rights, investigators, rights and legal framework for the } \\
\text { interaction between academia, start-ups and industry }\end{array}$ \\
\hline Ethical issues & $\begin{array}{l}\text { Knowledge of patients and animal rights and of medical and research ethics, understanding of university } \\
\text { and regulatory body rules for protocol development and support, and knowledge of risk-benefit analysis }\end{array}$ \\
\hline Communication skills & $\begin{array}{l}\text { Ability to talk to various audiences, prepare manuscripts and other documents, and interact between depart- } \\
\text { ments }\end{array}$ \\
\hline Preclinical testing & $\begin{array}{l}\text { Knowledge of regulatory requirements before clinical testing, ability to evaluate the viability of standard } \\
\text { operating procedures and ability to plan strategically to optimise resources }\end{array}$ \\
\hline $\begin{array}{l}\text { Design of preclinical } \\
\text { and clinical trials }\end{array}$ & $\begin{array}{l}\text { Knowledge of the process, challenges and concerns, ability to plan effectively, possession of critical thinking } \\
\text { skills to overcome challenges, ability to develop a protocol and ability to forge collaborations }\end{array}$ \\
\hline $\begin{array}{l}\text { Fundamental skill sets } \\
\text { (applies to all fields) }\end{array}$ & Networking, team-building and communication skills, and strategic thinking and creative problem solving \\
\hline
\end{tabular}

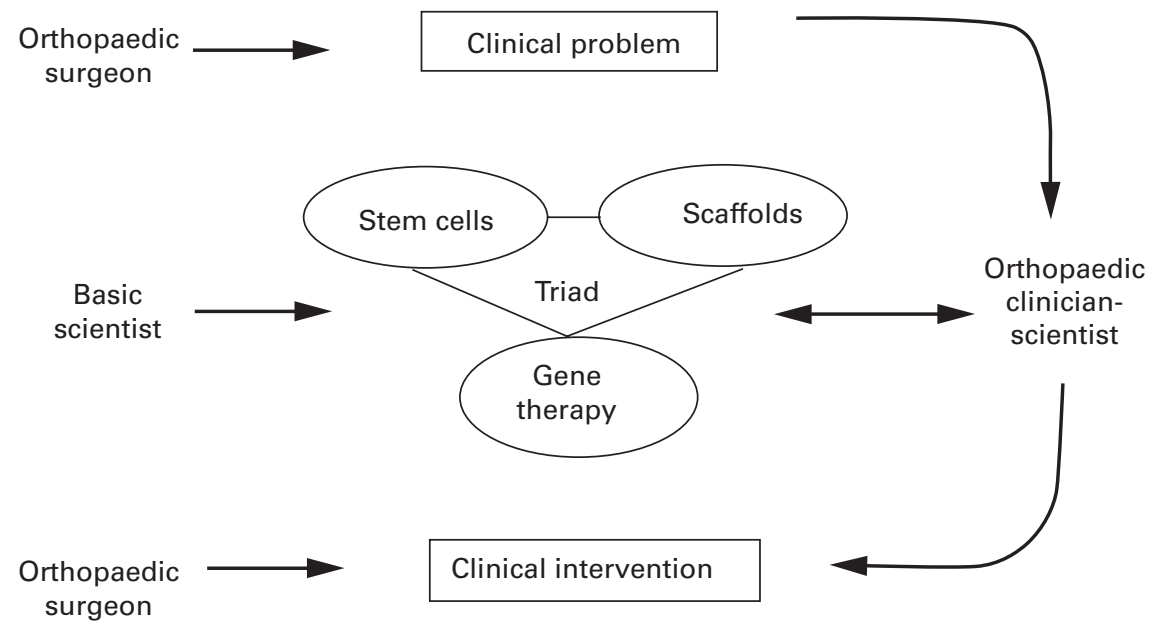

Fig. 1

Triad of tissue engineering and role of orthopaedic clinician-scientist. Because of the interaction of the clinician-scientist at all stages, they have a unique role to play in the process from discovery to intervention. These principles apply across all areas where orthopaedic basic science and clinical intervention interact.

\section{Integration of orthopaedic science and research}

Although we can be proud of much of current orthopaedic practice, focusing only on traditional surgical procedures may prevent the orthopaedic surgeons of the future from practising innovative approaches to musculoskeletal disorders. ${ }^{16}$ Individuals with varying experience and qualifications have practised orthopaedics for more than 2000 years. ${ }^{1}$ It would be reasonable to expect that, over this period, orthopaedic treatments would have become generally safe and effective. Yet, only 250 years ago, John Hunter (1728 - 1793), regarded as the father of scientific surgery, noted that "surgery, namely operations, is like an armed savage that attempts to get by force that which civilized men would get by stratagem". Orthopaedic operations in 
Extracellular matrix (ECM)

- Vital communication between cells and matrix molecules

- Scaffolds to provide binding sites for soluble and insoluble factors

Current research practice

- $\mathrm{ACl}$ remains the most common type of cell therapy for AC repairs

- Natural material scaffolds shown to be more suitable for supporting cell proliferation and matrix production

- MSCs are a potentially useful 'point of service' option for cell-based AC repair: they include both autogenic and allogeneic options

- The use of growth factors is limited by clinical availability, controlled release mechanisms and regulatory issues. Their in vitro actions have been extensively investigated and are being used for cell expansion and differentiation

- Molecules such as PTHrP are very useful in preventing chondrocyte hypertrophy and endochondral ossification

Future prospects

- Combination products likely to form the basis of future clinical applications

- Nanotechnology may improve material/scaffold design so the native matrix is simulated

- Stem cells +/- gene therapy an attractive option but will face problems secondary to drug regulatory pathway and safety profiles
Articular cartilage tissue engineering

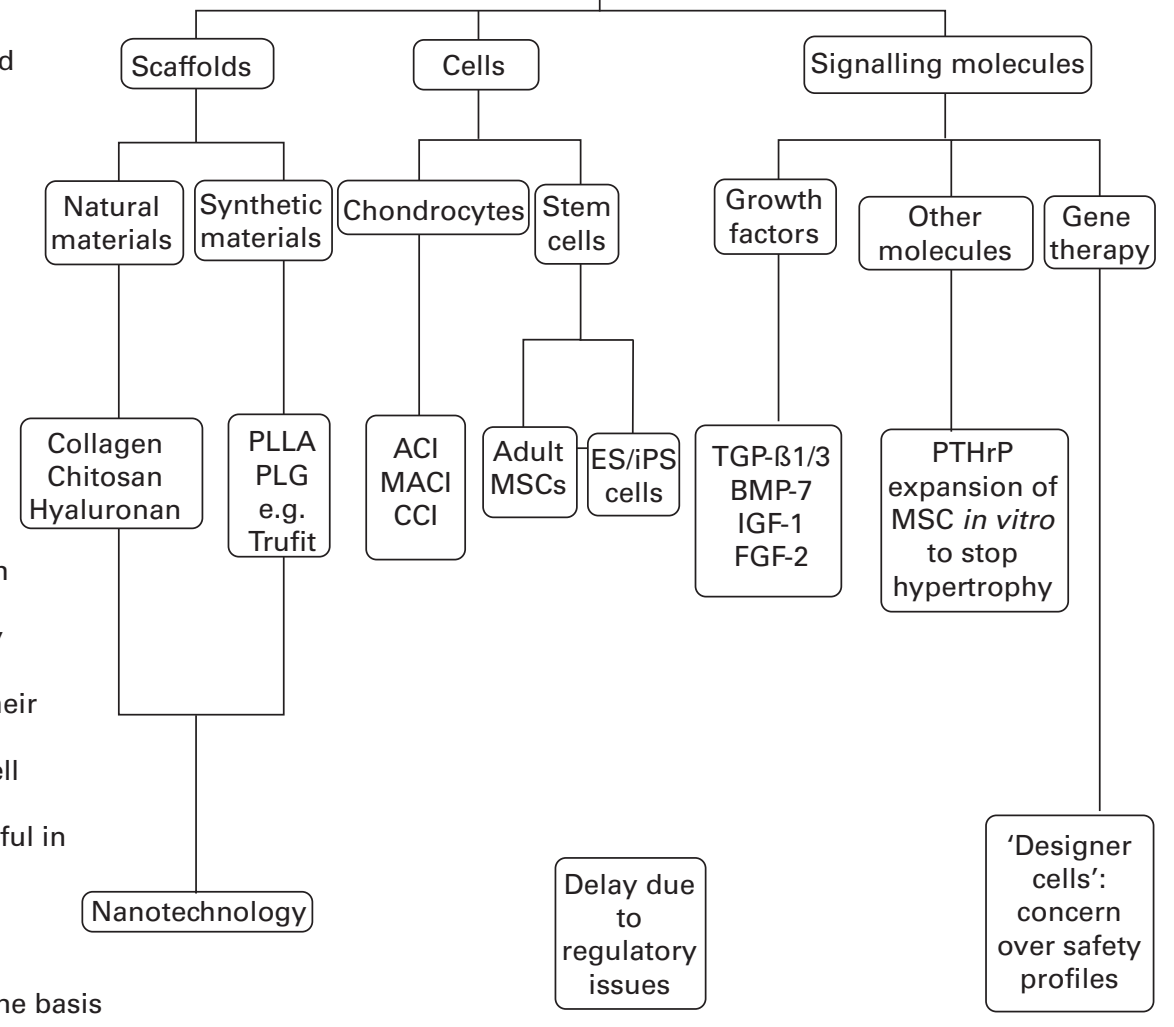

Fig. 2

Summary of current practice of articular cartilage tissue engineering (PLLA, poly-l-lactic acid; PLG, polylactide-co-glycolide; $\mathrm{ACl}$, autologous chondrocyte implantation; $\mathrm{MACl}$, matrix-assisted chondrocyte implantation; $\mathrm{CCl}$, characterised chondrocyte implantation; MSC, mesenchymal stem cell; ES, cell, embryonic stem cell; iPS cell, induced pluripotent stem cell; TGF- $\beta$ transforming growth factor- $\beta$; BMP, bone morphogenetic protein; IGF, insulin-like growth factor; FGF, fibroblast growth factor; PTHrP, parathyroid hormone-related peptide. Figure reproduced from Getgood et al, $J$ Bone Joint Surg [Br] 2009;91-B:565-76.

Hunter's day were painful, bloody, brutal, and dangerous. The typical results, for patients who survived, were disappointing and disabling. Orthopaedic practice was based on empiricism and the experience of surgeons, not on basic research or comparison of treatments with natural history or alternative treatments. Because the immediate effects of most operative and manipulative treatments of bone and joint disorders are readily observable, empiricism was a reasonable and attractive basis for the initial practice of orthopaedic surgery. How, then, did we learn the value of integrating science into practice and performing critical objective evaluations of the results of treatment? Lord Lister (1827 - 1912) deserves much of the credit for this evolution and for making orthopaedic operations safer and more effective. ${ }^{1}$ He dedicated four decades of his life to research, teaching and clinical practice. He eagerly looked beyond what could be directly observed to advance the understanding of disease and healing, and did not hesitate to initiate new practices based on research. It took many years before the scientific work of Lister on preventing sepsis in surgery was accepted into the standard practices we take for granted today.

The initial rejection of Lister's integration of knowledge from basic research into clinical practice and his comparison of treated and untreated patients to evaluate efficacy now seems surprising, but can we say that we have gone on to replace empiricism with science as the basis of orthopaedic practice in general? If we look at some current practice, this transformation is not complete. For example, research into the repair of articular cartilage offers a focus for regen- 
erative medicine. We know that current interventions have limited success. We recognise that traditional arthroscopic lavage and debridement of osteoarthritic joints makes sense empirically. The removal of degenerated meniscal and cartilaginous tissue and reactive synovium or osteophytes makes the joint look better, and washing out free fragments of degenerated tissue seems beneficial. Unfortunately, surgeons and scientists have not developed a body of basic research that supports these attractive ideas, and the operation has been shown to be no more effective than a placebo procedure. ${ }^{17}$ Furthermore, applying high levels of energy to an articular surface can have unseen effects, including damage to the cartilage and subchondral bone, the long-term consequences of which remain unknown. As clinicians come under pressure to introduce other treatments such as stem cell therapy, gene therapy, cartilage transplantation and tissue engineering from experimental to clinical practice, the consequences may not be benign if we get it wrong. Orthopaedic surgeons must act as a patient advocate as well as a clinician and scientist. It is therefore essential to translate scientific knowledge to surgical treatment through mechanisms carefully prepared for this purpose.

\section{Promise of research in regenerative orthopaedic surgery}

Much of the current interest in orthopaedic surgery is in combining developments in tissue regeneration with surgical interventions. The ability to regenerate, or enhance repair, in cartilage, bone, menisci, ligaments and tendons, remains an important goal for researchers and surgeons. ${ }^{1-15}$ A review of current basic research in this area is not the aim of this paper, as such articles are already present in the literature. ${ }^{18-36}$ However, surgery for osteoarthritis and research into repair of articular cartilage provide an example of the need to link laboratory science closely with clinical practice. The principles involved may be applied throughout orthopaedic basic science and related clinical interventions. In the future it is likely that the laboratory will play an important complementary role to the operating theatre in many areas of orthopaedic surgery.

Current surgical intervention for early cartilage injury is offered in the form of autologous chondrocyte implantation, matrix-induced autologous chondrocyte implantation, microfracture techniques and osteochondral grafts. ${ }^{19-23}$ These procedures offer well-described benefit in carefully selected individuals, and may allow traditional arthroplasty to be delayed or deferred indefinitely. However, the cartilage that forms from these biological interventions, other than osteochondral grafting, which has additional potential morbidity, is not true hyaline cartilage as seen in the native joint, and is still prone to degenerative change requiring arthroplasty at a later stage. While continuing to improve our knowledge and application of arthroplasty surgery, we must consider whether the restoration of a lost or wounded portion of articular cartilage with new, well-formed perma- nent cartilaginous tissue is possible. Research in basic science suggests that the answer is 'yes', although its use clinically is not practicable. The pioneering work by the surgeon and scientist Sir John Charnley (1911 - 1982) offers us an excellent example of the importance of the link between clinic and laboratory in managing degenerative joint disease. Our understanding of the biology, pathophysiology and biomechanics of articular cartilage has increased dramatically, giving us a much better understanding of what we need to accomplish. This can form the foundation for methods of restoring a lost or damaged portion of articular cartilage with new tissue that preserves or restores joint function, providing an alternative to arthroplasty for early-stage disease. Getgood et $\mathrm{al}^{2}$ recently presented an excellent overview of cartilage tissue engineering (Fig. 2) in this journal. As clinical applications are developed it will be important to ensure a rigorous comparison of appropriate methods of treatment driven by clinical need and performed by clinicians. But how can this be achieved?

Expert clinicians have a difficult task in keeping up to date with the literature in addition to their service delivery requirements. The orthopaedic pharmaceutical and technology industry, which for many years was expected to carry discoveries across the divide, is now also struggling to do so. In either case, it would probably be unwise of surgeons to leave this work to outside groups, in industry or acadaemia. It is essential that surgeons who are subsequently responsible for performing the relevant operations engage with the process from the start. The resulting deficit is sometimes labelled the "valley of death', 37 and neither basic researchers, busy with discoveries, nor surgeons, busy with patients, appear keen to venture there. There are three basic requirements for bringing orthopaedic regenerative medicine safely to the patient: 1) scientists with an understanding of clinical problems; 2) surgeons with an understanding of science; and 3) critical scientific evaluation of the results of clinical practice.

\section{The orthopaedic clinician-scientist}

A safe and effective translation of research into clinical practice requires careful evaluation by highly trained clinical investigators with expertise in laboratory research and in the design of ethically and regulation-compliant clinical trials. For example, the European Union directive on Advanced Therapy Medicinal Products will regulate stem cell, gene therapy and combinations of these therapies with medical devices. This directive must be transposed into member state law by 2011. The surgeon who aims to translate basic research findings into clinical practice must understand modern regulatory affairs and clinical trial methodology, in addition to being trained in laboratory research and clinical practice (Fig. 1).

This issue has previously been considered in the United States. ${ }^{38-40}$ Over 30 years ago, James Wyngaarden, former director of the National Institute of Health, called attention to 'The Clinical Investigator as an Endangered Species'. 
Francis Moore, in $1976,{ }^{35}$ spoke of the unresolved conflict "between the operating room and the laboratory ... between the clinical pressures of care of the sick and the pursuit of science". In 2001, Douglas Jackson, former President of the AAOS, described common deterrants to the young orthopaedic surgeon becoming a clinicianscientist. ${ }^{35}$ It was noted then that rapid advances in biomedical science bring increasing complexity to basic research, making part-time laboratory attachments for clinical trainees increasingly unrealistic. A dramatic rise in research in the biotechnology and pharmaceutical industries was accompanied by movement of clinician-scientists in general from academic to industrial settings. Significantly, these factors are accompanied by the increasing complexity of research in human subjects due to a variety of factors, including an increasing awareness of the importance of patient protection, the responsible conduct of research, and research ethics. There is no existing structure within orthopaedic surgery that can bridge the organisations capable of reducing the impediments to the choice of research in career development. ${ }^{41-43}$ Surgeons often gain the most recognition and satisfaction from working in a busy practice. Consequently, less time is spent pursuing training in clinical research. Furthermore, the difference in earnings between those orthopaedic graduates entering either full-time or part-time private practice and those taking on an academic position may act as a deterrent. Ironically, this may be an even bigger issue for those trainees who elect to undertake a Fellowship in an international academic orthopaedic institute gaining additional subspecialty expertise prior to taking a consultant role in our university hospitals. The orthopaedic community might reverse these trends by focusing on early intervention and support for those orthopaedic clinician-scientists still in training. In this regard, appropriate mentoring, research training, funding and national structures will all play a major role. ${ }^{38-45}$

\section{Key issues in training the orthopaedic clinician- scientist}

Mentoring. Mentoring is a key component for the development of young clinician-scientists and a central role for leaders in academic medicine. ${ }^{44-53}$ The presence of a mentor is highly predictive of the attainment of higher levels of career development of young investigators, as measured by publications, grants, leadership, academic rank, income and job satisfaction. A mentoring relationship in the early years of professional life has been cited as a critical element in a productive career. It has been said that among MDs, $\mathrm{MD}-\mathrm{PhDs}$ and $\mathrm{PhD}$ investigators in departments of medicine, an enthusiastic and engaging mentor was a primary influence on the decision to undertake research. Mentors contribute to the priorities, academic styles and career patterns of future faculty members, and thus help shape medicine's future, bringing both instrumental and psychosocial support. It is noteworthy, however, that such mentor- ship has limited recognition in academic circles, although attempts have been made to reward this area of endeavour by the National Institute of Health (NIH). Mentorship is often neglected in orthopaedic surgery owing to the pressures of clinical service. However, if we are to develop effective leaders of orthopaedic practice it is essential that adequate structures are put in place to address this.

Medical school. Replenishment of the orthopaedic clinician-scientist pool begins with medical students. The future of orthopaedic surgery depends on the continuous influx of young people with creative and inquisitive minds, who are nurtured and trained to investigate novel frontiers dedicated to the advancement of knowledge and science as well as surgical technique. At present most graduating medical students will not participate in research after they establish their careers, although opportunities exist to stimulate interest during the undergraduate period. This may take the form of a small project as part of the standard medical curriculum followed by all students, or a summer research elective, either at home or internationally. Structures and funding for these summer programmes are provided by institutes such as the National Institute for Health Research and Wellcome Trust in the United Kingdom. ${ }^{51-53}$ Although there are relatively few consultant orthopaedic surgeons in positions with protected academic time, it should be possible for co-mentorship to take place between those consultants with research-generated higher degrees and principal investigators of scientific laboratories. The potential scientific development offered by the completion of an intercalated BSc programme in one of the basic medical sciences should also be harnessed, as these programmes offer potential future clinician-scientists a firm grounding in the principles of combining a research interest alongside a clinical one. These degree programmes are typically completed after the third or fourth medical year, and again funding is awarded on a competitive basis. The opportunities for engaging in orthopaedic-related research are wide ranging in view of the number of university-based research institutes engaging in musculoskeletal tissue engineering throughout the United Kingdom and Ireland. Furthermore, the international links established by current orthopaedic consultants who have previously completed sub-specialty fellowships at established international academic centres of excellence, should facilitate the placement of some students wishing to combine international travel with career development, either as part of summer research projects or, as research years leading to higher degrees. Another option in developing the orthopaedic clinician-scientist from the medical school stage is the medical-scientist programme that culminates with the receipt of the US-style MD-PhD degree. The decision to apply to this programme is usually taken in the undergraduate years. In the US, MD-PhDs account for $30 \%$ of all NIH grant awards even though they only account for $2.5 \%$ of all medical school graduates. ${ }^{46}$ Although not traditionally offered by medical schools in the United Kingdom and Ireland, as these programmes are 
developed here they will offer an additional route for early training of the orthopaedic clinician-scientist.

Postgraduate research training. Research training is often introduced at the postgraduate stage. For some, this is driven purely by the need to meet the minimum research requirements to successfully attain a training position or training number within orthopaedic surgery as a specialist registrar or equivalent. It has been suggested that all orthopaedic surgical trainees require some research education to 'instill the scientific discipline' in their approach to patient care. However, it may also have the added benefit of stimulating interest in research as part of an orthopaedic career: the so-called 'late bloomer effect'. As postgraduate surgical training programmes are modified, research training is something that can be included and given adequate recognition. Postgraduate degrees by module have recently been introduced in some institutes, and involve both taught modules and a research dissertation. ${ }^{54}$ Modules include research methods; protocol development, design and analysis; medical device design and development; healthcare ethics; law and clinical research; human factors and surgical error; surgery in developing countries; and leading and managing organisations/services. Including such modules in the training of orthopaedic surgeons would help raise interest and awareness of the prerequisites of quality research in the consultants of the future, while perhaps stimulating some to play a more active role as clinician-scientists.

Formal clinician-scientist training programmes. Despite the identified benefit of a brief period of surgical research for all trainees, such exposure is too short to produce clinicianscientists who can compete for extramural funding. The development of such individuals requires a hybrid training scheme resulting in the generation of skills that transcend the operating theatre and the laboratory. Formal structures to train clinician-scientists are now taking place as a result of special strategies in the United Kingdom and Ireland. Positions on these programmes are not ring-fenced for any particular specialty, and entry is by competition. These programmes allow for combined clinical training and $\mathrm{PhD}$ research from the start of specialty training. The primary benefits for trainees include protected research time, a structure for developing their research skills and interests, developing funding applications, forming contacts and networks, and the provision of a supported, structured approach to research. It is important that the orthopaedic speciality engages with these programmes and encourages those who are willing to undergo extended training to help deliver tissue-regenerative strategies to benefit our patients and to act as the key link between full-time clinician and the laboratory. These trainees have a requirement to meet the same examination standards as clinical trainees, and in addition, to reach the standards set by full-time $\mathrm{PhD}$ students and researchers in musculoskeletal laboratories. This requires the full support of their orthopaedic clinical colleagues and trainers. Particular support must come from directors of each individual deanery, so that those individuals successful in attaining a place on such integrated training programmes can deliver all the requirements of both their clinical and research training programmes.

Other examples include NIHR clinical lectureships, which are specialty training posts that incorporate academic training. Clinical lecturers spend $50 \%$ of their time undertaking specialist clinical training and $50 \%$ undertaking research or educationalist training. These posts are aimed at those who are advanced in their specialty training, have completed a research doctorate or equivalent, and show outstanding potential for continuing an academic career. The maximum duration of these posts is four years, and it is expected that they will complete their specialty training during this period. Alongside clinical training, they will be able to improve their academic skills and will be encouraged to apply for funding to support further post-doctoral or educationalist training.

Translational research initiative. A major development in the way orthopaedic clinician-scientist careers can be developed is through building links with models such as the National Consortium of Medical Research Institutions in the United States, funded through Clinical and Translational Science Awards by the NIH, which are working together to improve the way biomedical research is conducted nationwide. ${ }^{55}$ Members of the consortium share a common vision to reduce the time it takes for laboratory discoveries to become treatments for patients, to engage communities in clinical research and to train clinical and translational researchers. When fully implemented in 2012, about 60 institutions will be linked together in the discipline of clinical and translational science. The purpose of this programme, is to help institutions forge a uniquely transformative, novel and integrative academic home for clinical and translational science that has the resources to captivate, advance and nurture a cadre of well-trained multi- and inter-disciplinary investigators and research teams, create an incubator for innovative research tools and information technologies, and co-ordinate multi- and interdisciplinary research and research workers in order to introduce new knowledge and techniques into clinical practice. Similar efforts are also needed in Ireland and the United Kingdom. When our trainees travel to the United States on fellowships it may be of benefit to encourage the completion of such research modules at these institutes.

\section{The orthopaedic clinician-scientist at consultant level}

Most academic orthopaedic departments remain under immense pressure in relation to the delivery of clinical services. Training programmes for clinician-scientists will need to be longer than for traditional clinical training, and after such commitment by clinical trainers, academic mentors, programme sponsors and the trainees themselves, it is imperative that efforts are made to facilitate the role of the clinician-scientist in our hospitals and universities. There is a risk that, in the absence of appropriate departmental structures, those appointed in an academic role will be increasingly called upon to deliver clinical care, thereby 
reducing protected research time. It may be that in the future, sub-specialty areas practised clinically by orthopaedic clinician-scientists will have to be rationalised to reduce their overall clinical workload. It may make more sense for such individuals in the post-training phase to focus on clinical areas closely linked to their research. Clinical audit and issues relating to patient safety may also require a similar move. The mark of success of a senior clinician-scientist is the ability to gain extramural research support while continuing to deliver an excellent clinical service. It is reasonable to envisage a future where highly qualified members of an academic orthopaedic department with an aptitude for basic, clinical and translational research, are provided with the protected time and resources to focus attention on these. This will require a major change in service delivery by consultants in many orthopaedic institutions, and will warrant significant discussion. For departments that adapt and embrace such change, the benefits are likely to be seen in their ability to attract the best and brightest trainees of the future, coupled with research funding from both government and outside agencies, leadership roles, and a voice within the hospital and university setting. They will become a reliable source for directing new regenerative surgical approaches as they are encouraged by outside agencies. It is also important to develop mechanisms whereby the academic clinician-surgeon encourages research by clinicians. Health services and universities will need to collaborate in order to create adequate numbers of posts for academic orthopaedic surgeons.

\section{Conclusions}

There is much to be proud of in our orthopaedic heritage. The standard treatments of today, where properly executed, serve our patients well. The demand for orthopaedic surgeons has never been greater, given the enormous economic, social and personal impact of orthopaedic conditions. Traditional orthopaedic surgery offers immense benefit to those whose conditions require surgery and the service commitments of the orthopaedic surgeon are enormous. However, change is inevitable. The rapidly emerging field of regenerative orthopaedic surgery, which holds great promise for the generation of functional tissue substitutes, demonstrates the need to train a cadre of orthopaedic surgeons with extended research experience. It should be acknowledged that the final steps in translating orthopaedic tissue engineering repair from basic science to surgical intervention remains a challenge to surgeons and basic scientists, and will require close collaboration between academic clinicians, clinicians and scientists. Orthopaedic surgeons should remain very active in translational research related to the musculoskeletal system. This will be particularly important to ensure the efficient incorporation of laboratory research into clinical practice in emerging concepts for biological cartilage repair strategies. Progression of research knowledge into safe and effective new forms of treatment can be facilitated by formally trained orthopaedic clinical scientists. Structures are being established to meet this pressing need, both nationally and internationally, throughout all specialties in medicine. Patients with musculoskeletal disorders have much to gain if the specialty of orthopaedic surgery is actively engaged in and becomes a leader in this process.

\section{Supplementary material}

$\ddot{e}$ A further opinion by Professor E. Lee is available with the online version of this article on our website at www.jbjs.org.uk

No benefits in any form have been received or will be received from a commercial party related directly or indirectly to the subject of this article.

\section{References}

1. Buckwalter JA. Integration of science into orthopaedic practice: implications for solving the problem of articular cartilage repair. J Bone Joint Surg [Am] 2003;85A(Suppl 2):1-7.

2. Getgood A, Brooks R, Fortier L, Rushton N. Articular cartilage tissue engineering. J Bone Joint Surg [Br] 2009;91-B:565-76.

3. Khan Y, Yaszemski MJ, Mikos AG, Laurencin CT. Tissue engineering of bone: material and matrix considerations. J Bone Joint Surg [Am]2008;90-A(Suppl 1):36-42.

4. Moffat KL, Wang IN, Rodeo SA, Lu HH. Orthopedic interface tissue engineeering for the biological fixation of soft tissue grafts. Clin Sports Med 2009;28:157-76.

5. Tsiridis E, Velonis S, Limb D, Giannoudis PV. Tissue engineering approaches to rotator cuff tendon deficiency. Connect Tissue Res 2008;49:455-63.

6. van Osch GJ, Brittberg M, Dennis JE, et al. Cartilage repair: past and future: lessons for regenerative medicine. J Cell Mol Med 2009;13:792-810.

7. Vacanti CA. History of tissue engineering and glimpse into its future. Tissue Eng 2006;12:1137-42.

8. Spector M. Biomaterials-based tissue engineering and regenerative medicine solutions to musculoskeletal problems. Swiss Med Wkly 2006;136:293-301.

9. Hunziker E, Spector M, Libera J, et al. Translation from research to applications. Tissue Eng 2006;12:3341-64.

10. Lu L, Zhu X, Valenzuela RG, Currier BL, Yaszemski MJ. Biodegradable polymer scaffolds for cartilage tissue engineering. Clin Orthop 2001;391(Suppl):251-70.

11. Evans CH, Ghivizzani SC, Robbins PD. Orthopedic gene therapy in 2008. Mol Ther 2009;17:231-44.

12. Evans CH, Ghivizzani SC, Robbins PD. Gene therapy of the rheumatic diseases: 1998 to 2008. Arthritis Res Ther 2009;11:209.

13. Mithoefer K, McAdams TR, Scopp JM, Mandelbaum BR. Emerging options for treatment of articular cartilage injury in the athlete. Clin Sports Med 2009;28:25-40.

14. Soucacos PN, Johnson EO, Babis G. An update on recent advances in bone regeneration. Injury 2008;39(Suppl 2):1-4.

15. Lee K, Chan CK, Patil N, Goodman SB. Cell therapy for bone regeneration: bench to bedside. J Biomed Mater Res B Appl Biomater 2009;89:252-63.

16. Boden SD, Einhorn TA, Morgan TS, Rosi LL, Weinstein JN. An AOA critical issue: the future of the orthopaedic surgeon: proceduralist or keeper of the musculoskeletal system? J Bone Joint Surg [Am] 2005;87-A:2812-21.

17. Kirkley A, Birmingham TB, Litchfield RB, et al. A randomized trial of arthroscopic surgery for osteoarthritis of the knee. N Engl J Med 2008;359:1097-107.

18. Maher SA, Hidaka C, Cunningham ME, Rodeo SA. What's new in orthopaedic research. J Bone Joint Surg [Am] 2008;90-A:1800-8.

19. Miyama T, Engebretsen L, Yoshikawa H, Shino K. Cell-based therapy in articular cartilage lesions of the knee. Arthroscopy 2009;25:531-52

20. Görtz S, Bugbee WD. Allografts in articular cartilage repair. J Bone Joint Surg [Am] 2006;88-A:1374-84.

21. Lynn AK, Brooks RA, Bonfield W, Rushton N. Repair of defects in articular joints: prospects for material-based solutions in tissue engineering. J Bone Joint Surg [Br] 2004;86-B:1093-9

22. Hunziker EB. Articular cartilage repair: basic science and clinical progress: a review of the current status and prospects. Osteoarthritis Cartilage 2002;10:432-63.

23. Daher RJ, Chahine NO, Greenberg AS, Sgaglione NA, Grande DA. New methods to diagnose and treat cartilage degeneration. Nat Rev Rheumato/ 2009;5:599-607.

24. Petrigliano FA, McAllister DR, Wu BM. Tissue engineering for anterior cruciate ligament reconstruction: a review of current strategies. Arthroscopy 2006;22:441-51. 
25. Ge Z, Yang F, Goh JC, Ramakrishna S, Lee EH. Biomaterials and scaffolds for ligament tissue engineering. J Biomed Mater Res A 2006;77:639-52.

26. Sundelacruz S, Kaplan DL. Stem cell- and scaffold-based tissue engineering approaches to osteochondral regenerative medicine. Semin Cell Dev Biol 2009;20:646-55

27. Giannoudis PV, Einhorn TA, Marsh D. Fracture healing: the diamond concept. Injury 2007;38(Suppl 4):3-6.

28. Barry FP, Murphy JM. Mesenchymal stem cells: clinical applications and biological characterization. Int J Biochem Cell Bio/ 2004;36:568-84.

29. Kovacevic D, Rodeo SA. Biological augmentation of rotator cuff tendon repair. Clin Orthop 2008;466:622-33.

30. van Tienen TG, Hannink G, Buma P. Meniscus replacement using synthetic materials. Clin Sports Med 2009;28:143-56.

31. Kabdel R, Roberts S, Urban JP. Tissue engineering and the intervertebral disc: the challenges. Eur Spine J 2008;17(Suppl 4):480-91.

32. Madigan NN, Windebank AJ. Current tissue engineering and novel therapeutic approaches to axonal regeneration following spinal cord injury using polymer scaffolds. Respir Physiol Neurobiol 2009[Epub ahead of print].

33. Mao JJ, Vunjak-Novakovic G, Mikos AG, Atala A. Translational approaches in tissue engineering and regenerative medicine. Boston, London: Artech House, 2007:1-503.

34. Butler D. Translational research: crossing the valley of death. Nature 2008;453:840-2.

35. Jackson DW. The orthopaedic clinician-scientist. J Bone Joint Surg [Am] 2001;83A:131-5

36. Clawson DK. Cultivating a valuable hybrid: the orthopaedic clinician-scientist. J Bone Joint Surg [Am] 2001;83-A:1432-3.

37. Wright JG. Supporting the orthopaedic clinician-scientist. J Bone Joint Surg [Am] 2002;84-A:145-6.

38. Einhorn TA. Funding the mandate for the orthopaedic clinician scientist. Clin Orthop 2006;449:76-80.

39. Brand RA, Hannafin JA. The environmental of the successful clinician-scientist. Clin Orthop 2006:449:67-71.
40. Rosier RN. Institutional barriers to the orthopaedic clinician-scientist. Clin Orthop 2006:449:159-64.

41. Hare GM. Challenges and rewards of the clinical scientist career path. Clin Invest Med 2008;31:e302-3.

42. Armstrong PW. A time for transformative leadership in academic health sciences. Clin Invest Med 2007;30:e127-32.

43. Tunbridge M. Monitoring the clinician scientist scheme. Clin Med 2004;4:141-3.

44. Wyngaarden JB. The clinical investigator as an endangered species. N Eng/ J Med 1979:301:1254-9.

45. Holcombe RF. Viewpoint: who's watching out for the clinical academician? Acad Med 2005;80:905-7

46. Ahn J, Man LX, Wanderer J, Bernstein J, lannotti JP. The future of the orthopaedic clinician-scientist. Part I: the potential role of MD-PhD students considering orthopaedic surgery. J Bone Joint Surg [Am] 2008;90-A:1794-9.

47. Rosenberg L. Physician-scientists: endangered and essential. Science 1999;283:331-2.

48. Gill G. The end of the physician scientist? Am Scholar 1984:53:353-68

49. Folkman J. Surgical research: a contradiction in terms? J Surg Res 1984;36:294-9.

50. Hurwitz SR, Buckwalter JA. The orthopaedic surgeon scientist: an endangered species? J Orthop Res 1999;17:155-6.

51. NHS National Institute for Health Research. www.nihr.ac.uk/ date last accessed 29 September 2009).

52. Health Research Board. www.hrb.ie (date last accessed 29 September 2009).

53. The Wellcome Trust. www.wellcome.ac.uk/ (date last accessed 29 September 2009)

54. Royal College of Surgeons in Ireland, Master of Surgery (MCh) by Module. www.rcsi.ie (date last accessed 29 September 2009).

55. National Institutes of Health Department of Health and Human Services Clinical and Translational Science Awards. www.ncrr.nih-gov/clinical_research_resources/ clinical and translational_science awards/(date last accessed 29 September 2009). 